JOEAI (Journal of Education and Instruction)

Volume 2, Nomor 2, Desember 2019

e-ISSN : 2614-8617

p-ISSN : 2620-7346

DOI: https://doi.org/10.31539/joeai.v2i2.931

\title{
MOTIVASI PUSTAKAWAN DALAM MENGIKUTI KEGIATAN DIKLAT TRAINING OR TRAINERS (TOT)
}

\author{
Sutriono \\ Institut Agama Islam Negeri (IAIN) Bengkulu \\ trionolibrarian@gmail.com
}

\begin{abstract}
ABSTRAK
Penelitian ini bertujuan untuk mengetahui motivasi baik intrinsic dan ektrinsik yang mendorong para pustakawan untuk mengikuti kegiatan diklat Training For Trainers (TOT) Tahun 2019 yang dilaksanakan selama 20 hari dan dikuti oleh para pustakawan yang sudah memasuki usia diatas lima puluh tahun. Metode yang digunakan dalam penelitian ini adalah deskriptif kualitatif. Sampel dalam penelitian ini adalah pustakawan sebanyak 30 orang yang diambil dengan total sampling. Data yang diperlukan didapat dengan metode wawancara dan observasi langsung di lapangan. Hasil penelitian, sebanyak 18 responden (60\%) menyampaikan motivasi mengikuti TOT berasal dari faktori internal, dari faktor internal ini sebanyak 18 responden $(60 \%)$ mengaku ingin meningkatkan wawasan dan keterampilan (skill) tentang diklat kepustakawanan, adapun dari faktor eksternal karena ingin mendapatkan SIM/legalitas untuk mengajar diklat teknis/fungsional kepustakawanan yang diakui oleh 16 responden (53\%). Simpulan, motivasi paling kuat yang melatar belakangi pustakawan mengikuti kegiatan diklat Training For Trainers (TOT) angkatan tahun 2019 adalah kebutuhan untuk menambah wawasan dan keterampilan menjadi pelatih/instruktur perpustakaan, selain untuk mendapatkan legalitas dalam mengajar diklat teknis/fungsional kepustakawanan.
\end{abstract}

Kata Kunci : Jiwa Pembelajar, Motivasi Pustakawan, Training of Trainers

\section{ABSTRACT}

This study aims to determine both intrinsic and extrinsic motivations that encourage librarians to take part in the 2019 Training For Trainers (TOT) training activities which are held for 20 days and are followed by librarians who have entered the age above fifty years. The method used in this research is descriptive qualitative. The sample in this study were 30 librarians taken by total sampling. The data needed is obtained by interview and direct observation in the field. The results of the study, as many as 18 respondents (60\%) conveyed the motivation to follow TOT derived from internal factors, from these internal factors as many as 18 respondents (60\%) claimed to want to improve their insights and skills about librarian training, as for external factors because they wanted to get SIM / legality to teach librarian technical / functional training recognized by 16 respondents (53\%). In conclusion, the strongest motivation behind the librarian following the 2019 Training For Trainers (TOT) training activity was the need to add insight and skills to become library trainers I 
instructors, in addition to getting legality in teaching technical / functional librarian training.

Keywords: Learning Soul, Librarian Motivation, Training of Trainers

\section{PENDAHULUAN}

Dalam Undang undang Nomor 43 tahun 2007 (UU NO. 43 Tahun 2007) Tentang Perpustakaan dijelaskan bahwa Pustakawan adalah seseorang yang memliki kompetensi yang diperoleh melalui pendidikan dan/atau pelatihan kepustakawanan serta mempunyai tugas dan tanggung jawab untuk melaksanakan pengelolaan dan pelayanan perpustakaan (UUD No 43 Tahun 2007), selain itu lebih spesifik lagi dalam Peraturan Menteri Pemberdayaan Aparatur Negara dan RB Nomor 09 tahun 2014 definisi pustakawan adalah Pegawai Negeri Sipil (PNS) yang diberi tugas, tanggung jawab, wewenang dan hak untuk melaksanakan kegiatan kepustakawanan (Menpan RB RI, 2014).

Mengingat tugas pustakawan di perpustakaan adalah sebagai pejabat yang berwenang mengelola perpustakaan dimana salah satu amanah UU 43 tahun 2007 pada pasal 1 menjelaskan bahwa Perpustakaan adalah institusi pengelola koleksi karya tulis, karya cetak, dan atau/karya rekam secara profesional dengan sistem yang baku guna memenuhi kebutuhan pendidikan, penelitian, pelestarian, informasi dan rekreasi para pemustaka, oleh karena itu pustakawan harus memiliki kompetensi dan keterampilan yang harus terus menurus ditingkatkan seiring dengan perubahan kemajuan teknologi informasi.

Kenretno (2010) dalam sebuah tulisan di blognya menguraikan, pustakawan adalah mitra intelektual yang memberikan jasanya kepada pengguna dengan kemampuan berkomunikasi yang bagus, baik secara lisan maupun tulisan. Oleh karena itu pustakawan dengan kriteria-kriteria berikut sangat diperlukan sebagai people skills yang kuat, yaitu : Pemecahan masalah (kreatifitas, pencair konflik), Etika (diplomasi, jujur, profesional), Terbuka (fleksibel, terbuka untuk wawasan bisnis, berpikir positif), Perayu (ketrampilan komunikasi dan mendengarkan atentif), Kepemimpinan (bertanggung jawab dan kemampuan memotivasi), berminat belajar (haus akan pengetahuan dan perkembangan).

Dengan kompleksitas tugas dan tanggungjawabnya mengelola perpustakaan, pustakawan hari ini juga mempunyai peluang untuk mengembangkan kariernya melalui lembaga pendidikan kepustakawanan yaitu menjadi calon-calon instruktur guna mendidik dan membina pustakawan lain untuk meningkatkan keahliannya. Erni Susilowati (2007) pernah melakukan penelitian yang berjudul motivasi pustakawan Perguruan Tinggi Negeri (PTN) Daerah Istimewa Yogyakarta (DIY) dalam penulisan artikel yang dipublikasikan media cetak, persoalanya adalah pustakawan sebagai praktisi yang berada di tengah-tengah sumber informasi berupa buku dan lainya akan tetapi di lapangan masih sedikit yang melakukan penulisan di media cetak. Hasil dari penelitian ini 
ditemukan bahwa (1) Motivasi paling kuat yang melatarbelakangi pustakawan dalam menulis artikel di media cetak adalah motivasi angka kredit, dengan skor 3,81. (2) Motivasi intrinsik lebih besar pengaruhnya daripada motivasi ekstrinsik dalam mendorong pustakawan untuk menulis artikel di media cetak. (3) Hal yang mempengaruhi motivasi pustakawan untuk menulis artikel di media cetak adalah jenjang kepustakawanan, tingkat pendidikan, dan keikutsertaan dalam pelatihan teknik penulisan. (4) Hal yang kurang mempengaruhi motivasi pustakawan untuk menulis artikel di media cetak, antara lain usia, jenis kelamin, dan lamanya bekerja di perpustakaan.

Menurut penulis, motivasi pustakawan dalam mengikuti pendidikan dan pelatihan Training of Trainer (TOT) angkatan 2019 ini menarik untuk diteliti karena saat ini untuk mengikuti diklat harus menunggu lama sebagaimana penulis alami telah menunggu dari tahun 2016 atau 3 tahun yang lalu. Apakah kemudian faktor-faktor untuk menulis sebagaimana penelitian Erni Susilowati (2007) juga berbanding lurus dengan motivasi pustakawan untuk mengikuti pendidikan dan pelatihan Training of Trainer (TOT) angkatan 2019. Tulisan ini akan mencoba untuk mencari jawabannya, ada manfaat lebih dengan diketahui nya motivasi apa yang mendorong pustakawan dalam mengikuti TOT seperti informasi bagi lembaga perpustakaan untuk meningkatkan mutu pustakawan yang ada.

\section{METODE PENELITIAN}

Penelitian ini adalah penelitian lapangan dengan menggunakan pendekatan kualitatif yang lebih menekankan analisisnya pada proses penyimpulan deduktif dan induktif serta pada analisis terhadap dinamika hubungan fenomena yang diamati dengan menggunakan logika ilmiah yang bersifat kualitatif, yaitu pemecahan masalah yang sedang dihadapi pada waktu sekarang yang dilakukan dengan cara menempuh langkah-langkah penyimpulan, pengidentifikasi, menganalisa data dan membuat laporan dengan tujuan untuk mendeskripsikan/gambaran tentang suatu keadaan sesuai apa adanya dari data yang diperoleh di lapangan.

Penelitian ini dilakukan terhadap para pustakawan yang mengikuti kegiatan diklat Training For Trainers (TOT) tahun 2019, yang di laksanaan pada bulan Agustus 2019. Subjek penelitian ini adalah pustakawan yang mengkuti kegiatan diklat Training of Trainers (TOT). Variabel motivasi pustakawan dalam kegiatan diklat Training For Trainers (TOT) tahun 2019 dapat dilihat atau dibedakan dari berbagai segi, yaitu dari tingkat pendidikan, pengalaman kerja, usia, dan jenis kelamin. Tingkat pendidikan dapat dikategorikan sarjana dan Pascasarjana. Dari segi pengalaman kerja bisa dikategorikan dari lamanya menjadi pustakawan atau bekerja di perpustakaan. Dari segi jenis kelamin yaitu laki-laki dan perempuan. Pengumpulan data dilakukan melalui wawancara langsung dan tidak langsung selama proses diklat dilaksanakan. Analisis data dilakukan untuk mengetahui motivasi masing-masing pustakawan. 


\section{HASIL DAN PEMBAHASAN}

Hasil penelitian ini diperoleh melalui penyebaran angket yang penulis ajukan kepada responden berisikan hal-hal yang berkaitan langsung dengan motivasi Pustakawan untuk mengikuti diklat Training For Trainer (TOT) Perpustakaan Nasional RI yang diselenggarakan pada bulan Agustus 2019 sebanyak 30 orang, dengan rincian asal instansi/lembaga responden sebagai berikut; Perpustakaan Nasional RI sebanyak 8 orang, Dinas Perpustakaan dan Kearsipan Propinsi/Kabupaten sebanyak 11 orang, Perpustakaan Perguruan Tinggi sebanyak 6 orang, Kementerian/lembaga sebanyak 5 orang.

Pertanyaan terdiri dari 3 item soal terkait motivasi yang telah disediakan alternatif jawaban a, b dan c. Hasil jawaban responden penulis sajikan sebagai berikut:

Tabel 1.

Faktor yang mempengaruhi motivasi pustakawan dalam mengkuti diklat TOT

\begin{tabular}{cllcc}
\hline \multirow{2}{*}{ No. } & & \multicolumn{1}{c}{ Alternatif Jawaban } & Jumlah & Prosentase (\%) \\
\hline \multirow{3}{*}{1} & A. & Internal & 18 & $60 \%$ \\
\cline { 2 - 5 } & B. & Eksternal & 2 & $7 \%$ \\
\cline { 2 - 5 } & C. & Lainnya & 0 & $0 \%$ \\
\cline { 2 - 5 } & D. & Tidak menjawab & 10 & $33 \%$ \\
\cline { 2 - 4 } & \multicolumn{2}{c}{ Jumlah } & 30 & $100 \%$ \\
\hline
\end{tabular}

Dari tabel di atas menunjukkan bahwa responden yang menjawab karena faktor Internal sebanyak 18 orang atau $60 \%$. responden yang menjawab karena faktor Eksternal sebanyak 2 orang atau 7\% serta tidak memberikan jawaban sebanyak 10 orang atau orang atau 33\%. Hal ini menunjukkan bahwa motivasi pustakawan untuk mengikuti diklat TOT ini sangat dominan di pengaruhi oleh faktor internal (dari dalam diri pustakawan) itu sendiri.

Tabel 2.

Faktor internal yang menjadi alasan Pustakawan mengikuti diklat TOT

\begin{tabular}{cccc}
\hline No. & Alternatif Jawaban & Jumlah & Prosentase (\%) \\
\hline \multirow{3}{*}{1} & A & 18 & $60 \%$ \\
\cline { 2 - 4 } & B & 1 & $3 \%$ \\
\cline { 2 - 4 } & C & 1 & $3 \%$ \\
\cline { 2 - 4 } & D & 10 & $33 \%$ \\
\cline { 2 - 4 } & Jumlah & 30 & $100 \%$ \\
\hline
\end{tabular}

Dari tabel di atas menunjukkan bahwa responden yang menjawab karena ingin meningkatkan wawasan dan keterampilan (skill) tentang diklat kepustakawanan sebanyak 18 orang atau $60 \%$, yang menjawab karna Ingin menambah jejaring/teman sebanyak 1 orang atau 3\%, yang menjawab alasan lainya untuk meningkatkan soft skill bidang kepuatakawanan sebanyak 1 orang 
atau 3\%, sedangkan yang tidak memberikan jawaban sebanyak 10 orang atau atau $33 \%$. Hal ini menunjukkan bahwa motivasi pustakawan untuk mengikuti diklat TOT ini sangat dominan di pengaruhi oleh faktor internal (dari dalam diri pustakawan) itu sendiri berupa ingin meningkatkan wawasan dan keterampilan (skill) tentang diklat kepustakawanan.

Tabel 3.

Faktor eksternal yang mempengaruhi pustakawan mengikuti diklat TOT

\begin{tabular}{cccc}
\hline No. & Alternatif Jawaban & Jumlah & Prosentase (\%) \\
\hline \multirow{3}{*}{1} & $\mathrm{~A}$ & 16 & $53 \%$ \\
\cline { 2 - 4 } & $\mathrm{B}$ & 1 & $3 \%$ \\
\cline { 2 - 4 } & $\mathrm{C}$ & 3 & $10 \%$ \\
\cline { 2 - 4 } & $\mathrm{D}$ & 10 & $33 \%$ \\
\hline
\end{tabular}

Dari tabel di atas menunjukkan bahwa responden yang menjawab karena Ingin mendapatkan SIM/legalitas untuk mengajar diklat teknis/fungsional kepustakawanan sebanyak 16 orang atau 53\%. Responden yang menjawab untuk memenuhi kewajiban pengembangan kompetensi 20 jp sebanyak 1 orang atau 3\% dan yang menjawab alasan lainnya karena diminta atasan/pimpinan sebanyak 3 orang atau $10 \%$, sedangkan yang tidak memberikan jawaban sebanyak 10 orang atau orang atau 33\%. Hal ini menunjukkan bahwa faktor dari luar yang mempengaruhi diri pustakawan untuk mengikuti diklat TOT ini sangat dominan di pengaruhi oleh faktor karena Ingin mendapatkan SIM/legalitas untuk mengajar diklat teknis/fungsional kepustakawanan.

Berdasarkan temuan dilapangan dan wawancara singkat penulis dengan para pustakawan peserta diklat TOT angkatan 2019 bahwa motivasi yang mendorong para pustakawan untuk mengikuti kegiatan diklat Training For Trainers (TOT) yaitu motivasi dari dalam diri pustakawan (internal) itu sendiri maupun dari luar (eksternal) diri pustakawan.

Faktor internal antara lain kemauan dan minat untuk meningkatkan ilmu dan wawasan serta semangat jiwa pembelajar pustakawan yang tinggi mengingat tugas pustakawan yang sehari-harinya melayani dan memberikan informasi kepada pemustaka siapapun dan apapun latar belaknag pendidikannya sehingga diperlukan bekal ilmu pengetahuan yang luas, selain itu lembaga perpustakaan yang menjadi tempatnya bekerja adalah organisasi yang dinamis menerima informasi-informasi dan pengetahuan yang baru.

Hal ini sesuai dengan pendapat Notoatmodjo (2003) dimana tujuan Pendidikan dan Pelatihan pada hakikatnya adalah untuk membekali, meningkatkan, dan mengembangkan kompetensi kerja guna meningkatkan kemampuan, produktivitas, dan kesejahteraan. tujuan pelatihan ini utamanya adalah meningkatkan efektifitas atau hasil kerja pegawai, atau dengan kata lain 
adalah untuk meningkatkan efektivitas dan efisiensi kerja tiap pegawai. Menurut Simamora (dalam Ambar Teguh, 2004) beberapa tujuan Pelatihan adalah : a. Memperbaiki Kinerja Memutakhirkan keahlian para karyawan sejalan dengan kemajuan teknologi b. Mengurangi waktu belajar karyawan baru supaya menjadi kompeten dalam pegawai c. Membantu memecahkan persoalan operasional $\mathrm{d}$. Mempersiapkan karyawan untuk promosi e. Memenuhi kebutuhan-kebutuhan pertumbuhan pribadi.

Sedangkan dari faktor eksternal berdasarkan hasil penelitian diantaranya adalah dengan selesainya mengikuti diklat TOT ini pustakawan akan mendapatkan legalitas semacam "SIM" untuk bisa menjadi pengajar pada lembaga kediklatan yang pada saat ini widyaiswara nasional masih terbatas, maka melalui kegiatan ini pustakawan akan dapat dilibatkan untuk memberikan pelatihan dan pendidikan sebagaimana yang telah ditetapkan ketentuannya oleh Pusat Pendidikan dan Pelatihan Perpusnas RI.

Hal ini sebagaimana menurut pendapat Luthan dalam Muljono (2002) bahwa motivasi terkait erat dengan kebutuhan, dorongan, dan tujuan. Dengan kata lain, pustakawan mengikuti Diklat TOT ini adalah suatu tuntutan kebutuhan skils profesi yang tidak bisa diabaikan serta memiliki tujuan agar setelah mengikuti kegiatan ini pustakawan bisa berperan aktif dalam meningkatkan mutu dan skils rekan-rekan pengelola perpustakaan dehingga mampu meningkatkan kinerja dan layanannya di perpustakaan, lebih lanjut Luthan menjelaskan biasanya motivasi terkait dan berhubungan erat dengan kebutuhan, dorongan, dan tujuan. Dengan kata lain, motivasi merupakan dorongan yang ada pada diri manusia yang menjadi energi, aktivitas dan gerakan yang mengarahkan perilaku untuk mencapai tujuan.

\section{SIMPULAN}

Dari uraian diatas dapat penulis simpulkan motivasi paling kuat yang melatar belakangi pustakawan mengikuti kegiatan diklat Training For Trainers (TOT) angkatan tahun 2019 sebanyak $60 \%$ adalah faktor internal yaitu keinginan untuk menambah wawasan dan keterampilan menjadi pelatih/instruktur perpustakaan. Selain itu kebutuhan meningkatkan keterampilan sebagai profesi yang tidak bisa ditawar lagi mengingat era informasi dan teknologi digital hari ini serta memiliki tujuan agar setelah mengikuti kegiatan ini pustakawan bisa berperan aktif dalam meningkatkan mutu dan keahlian pustakawan untuk meningkatkan kinerja dan layanannya di perpustakaan dengan persyaratan telah memiliki sertifikat diklat TOT Perpusnas RI. 


\section{DAFTAR PUSTAKA}

Ambar, T., S. (2004). Kemitraan dan Model-Model Pemberdayaan. Yogyakarta : Graha Ilmu.

Dina, H. (2014). Hubungan Pendidikan dan Pelatihan dengan Kinerja Pegawai di Dinas Perhubungan Kota Samarinda. e-Journal llmu Administrasi Negara $4(2)$.

Erni, S. (2007). Motivasi pustakawan Perguruan Tinggi Negeri (PTN) Daerah Istimewa Yogyakarta (DIY) dalam penulisan artikel yang dipublikasikan di media cetak. Berkala Ilmu Perpustakaan dan Informasi 3(6). diunduh dari https://jurnal.ugm.ac.id/bip/article/view/8268/6397.

https://kbbi.kemdikbud.go.id/entri/pelatihan diunduh tanggal 4 Agustus 2019 pukul 08.40 WIB

Kenretno. (2010). Pustakawan Sebagai Garda Pengetahuan. di unduh dari http://kenretno.blogspot.com/2010/03/pustakawan-sebagai-gardapengetahuan.html di unduh tanggal 4 Agustus 2019 pukul 08.30 wib

Mardalis. (2008). Metode Penelitian Suatu Pendekatan Proposal. Jakarta : PT. Bumi Aksara.

Dimyati dan Mulyono. (2002). Belajar dan Pembelajaran. PT Rineka Cipta.

Nasution. (2003). Metode Penelitian Naturalistik Kualitatif. Bandung: Tarsito.

Notoatmodjo, S. (2003). Pendidikan Dan Perilaku Kesehatan. Jakarta:Rineka. Cipta.

Republik Indonesia, Undang undang (UU) Nomor 20 tahun 2003 tentang Sistem Pendidikan Nasional

Republik Indonesia, Undang undang Nomor 43 tahun 2007 tentang Perpustakaan Republik Indonesia. (2014). Peraturan Menteri Pendayagunaan Aparatur Negara dan Reformasi Birokrasi Republik Indonesia Nomor 9 Tahun 2014 Tentang Jabatan Fungsional Pustakawan Dan Angka Kreditnya.

Susilowati, E. (2007). Motivasi pustakawan Perguruan Tinggi Negeri (PTN) Daerah Istimewa Yogyakarta (DIY) dalam penulisan artikel yang dipublikasikan media cetak, Jurnal Berkala Ilmu Perpustakaan dan Informasi 3(6). 